\title{
BMJ Open Diabetes and cardiovascular disease risk screening model in community pharmacies in a developing primary healthcare system: a feasibility study
}

\author{
Hamzah Tareq Alzubaidi (D) , ${ }^{1}$ Subhash Chandir, ${ }^{2}$ Sanah Hasan, ${ }^{3}$ \\ Kevin McNamara, ${ }^{4,5}$ Rachele Cox, ${ }^{2}$ Ines Krass ${ }^{6}$
}

To cite: Alzubaidi HT, Chandir S, Hasan S, et al. Diabetes and cardiovascular disease risk screening model in community pharmacies in a developing primary healthcare system: a feasibility study. BMJ Open 2019;9:e031246. doi:10.1136/ bmjopen-2019-031246

- Prepublication history for this paper is available online. To view these files, please visit the journal online (http://dx.doi. org/10.1136/bmjopen-2019031246).

Received 02 May 2019 Revised 29 September 2019 Accepted 07 0ctober 2019

Check for updates

(C) Author(s) (or their employer(s)) 2019. Re-use permitted under CC BY-NC. No commercial re-use. See rights and permissions. Published by BMJ.

For numbered affiliations see end of article.

Correspondence to Dr Hamzah Tareq Alzubaidi; halzubaidi@sharjah.ac.ae

\section{ABSTRACT}

Objectives This study aimed to develop an evidencebased community pharmacist-delivered screening model for diabetes and cardiovascular disease (CVD), and assess its feasibility to identify and refer patients with elevated risk.

Design A feasibility study.

Setting A purposive sample of 12 community pharmacies in three cities in the United Arab Emirates (UAE).

Participants Adults 40 years of age and above who have not been previously diagnosed with either diabetes or CVD. Intervention Pharmacist screening of adults visiting pharmacies involved history, demographics, anthropometric measurements, blood pressure and pointof-care testing including glycated haemoglobin ( $\mathrm{HbA1c}$ ) levels and lipid panel. Participants with a 10-year CVD risk $\geq 7.5 \%$, HbA1c level $\geq 5.7 \%$ or American Diabetes Association (ADA) risk score $\geq 5$ points were advised to visit their physician.

Primary and secondary outcome measures The primary outcomes were (1) development of UAE pharmacist-delivered screening model, (2) the proportion of screened participants identified as having high CVD risk (atherosclerotic CVD 10-year risk defined as $\geq 7.5 \%$ ) and (3) the proportion of participants identified as having elevated blood glucose (high HbA1c level $\geq 5.7 \%$ (38.8 $\mathrm{mmol} / \mathrm{mol}$ )) or high self-reported diabetes risk (ADA risk score $\geq 5$ points). Secondary outcome is participants' satisfaction with the screening.

Results The first UAE pharmacist-delivered screening model was developed and implemented. A total of 115 participants were screened, and $92.3 \%$ of the entire screening process was completed during a single visit to pharmacy. The mean duration of the complete screening process was $27 \mathrm{~min}$. At-risk individuals (57.4\%) were referred to their physicians for further testing, while $94.5 \%$ of participants were at least satisfied with their screening experience.

Conclusions The community pharmacist-delivered screening of diabetes and CVD risk is feasible in the UAE. The model offers a platform to increase screening capacity within primary care and provides an opportunity for early detection and treatment. However, pathways for the integration of the pharmacist-delivered screening service with physicians in primary care are yet to be explored.
Strengths and limitations of this study

- An expert panel was used to adapt an international screening and develop the first contextually tailored pharmacy screening model for diabetes and cardiovascular diseases risk in the United Arab Emirates.

- Lipid panel and glycated haemoglobin level were measured using a finger-prick point-of-care testing device (Roche Cobas b 101 POC dual system).

- Follow-up with physicians on referral outcomes of participants at risk could not be determined due to the fragmented healthcare system. We relied on patient self-report data.

- Patient recruitment heavily relied on a direct invitation from pharmacists.

- Follow-up times with screened participants were short and may not have encompassed all results regarding follow-up with physicians.

\section{INTRODUCTION}

Type 2 diabetes mellitus (T2DM) and cardiovascular disease (CVD) are the leading contributors to the global burden of disease, although with distinct long-term trends. ${ }^{1}$ Diabetes, a rapidly growing global epidemic, affects all countries and is substantially caused by rapidly increasing rates of obesity over recent decades. ${ }^{2}$ By 2040, T2DM will affect an estimated 642 million people; $10.4 \%$ of the adult population, compared with $8.8 \%$ in 2015. ${ }^{2-4}$ Age-standardised CVD trends are more geographically nuanced-generally, the incidence has declined markedly in highly developed countries over several decades, but this decline has now plateaued. ${ }^{5}$ Likewise, some middle-income regions have experienced declines in CVD mortality, but in most regions of the developing world, a rapid increased incidence has recently prevailed. ${ }^{5}$ Globally, in 2015, there were an estimated 422.7 million prevalent cases of CVD, and ischaemic heart disease and stroke remained 
the leading causes of death. ${ }^{5}$ A combination of an ageing western society and increasing CVD mortality rates in many developing regions has resulted in increasing CVDrelated deaths from 12.6 million in 1990 to 17.9 million in 2015. ${ }^{5}$ Both CVD and diabetes represent major public health challenges in all countries. Globally, CVD affects $32.2 \%$ of all persons with T2DM. ${ }^{6}$

An estimated $45.8 \%$ (174.8 million) of adult diabetes cases worldwide are undiagnosed, ranging from $24.1 \%$ to $75.1 \%$ in different countries. ${ }^{7}$ Overall, the prevention and delay of diabetes complications are facilitated by combining early detection of undiagnosed diabetes using population or opportunistic screening approaches with effective prevention interventions. ${ }^{8-10}$

In Arabic-speaking countries, the prevalence of T2DM is at alarming levels with high morbidity and mortality rates. ${ }^{11}$ Six Arabic-speaking countries (Kuwait, Lebanon, Qatar, the United Arab Emirates (UAE), Saudi Arabia and Bahrain) lead the world in the prevalence of T2DM, affecting approximately one in five people. ${ }^{12}$ There is an urgent need to increase capacity for the detection of diabetes and to reduce its burden in these Arabicspeaking countries. Previous research has identified negative health beliefs, poor health-seeking behaviours and intentional delay in accessing available medical services are commonplace in Arabic-speaking communities, hence the need for proactive and opportunistic population screenings. ${ }^{13-15}$

The feasibility of pharmacist-delivered screening, for a variety of conditions including diabetes and CVD, is well supported by evidence. ${ }^{16}{ }^{17}$ Such screening interventions identified at-risk individuals and increased rates of disease diagnosis, reduced disease risk factors, improved health behaviours, enhanced quality of care and increased patient knowledge and awareness. ${ }^{18}$ Community pharmacists have face-to-face contact with around $90 \%$ of the population annually and appear to interact regularly with those who have elevated risk of diabetes and CVD, or undiagnosed diabetes. ${ }^{19}$ The potential, therefore, exists for pharmacists to improve access to health screening services and promote public health awareness.

In the UAE, a substantial number of people with diabetes and a high prevalence of overweight and obesity are currently thought to remain undiagnosed. ${ }^{20}$ There are around 2500 licensed community pharmacies in UAE that are generally open 7 days per week, easily accessible and have an average working day of 13 hours $^{21}{ }^{22}$; this potentially makes pharmacies an effective setting to offer screening for diabetes and CVD within the primary care system. To our knowledge, no systematic diabetes and CVD screening programme exist in the primary care setting in the UAE, meaning these diseases continue to be undiagnosed precluding the opportunity to initiate early prevention and treatment.

The aim of this study was to test the feasibility of pharmacist-delivered diabetes and CVD risk screening model in the UAE. The specific objectives were to
1. Develop locally appropriate pharmacist-delivered diabetes and CVD risk screening model for the community pharmacies in UAE.

2. Evaluate the feasibility of implementing diabetes and CVD risk screening model in the selected community pharmacies in the UAE.

\section{METHODS}

\section{Study design}

The study was conducted in three phases: phase I (formative phase) explored development of a suitable model for diabetes screening and CVD risk assessment in community pharmacies in the UAE, phase II (implementation phase) assessed the feasibility of the screening model and phase III (evaluation phase) tested the impact of the screening model.

\section{Phase l: formative phase}

A systematic approach was used to develop the intervention of diabetes and CVD screening. ${ }^{23}$ The formative phase commenced with identifying the needs for diabetes and CVD risk screening programme. After identifying the suitability of community pharmacies for providing screening services, a literature review of pharmacist-delivered screening models was conducted to identify useful and effective approaches to screening. The Australian Cardiovascular Absolute Risk Screening Study (CARS) was considered an appropriate template model to inform the development of the first UAE pharmacy-based screening programme. ${ }^{24}$ Two local health professionals were consulted to determine the adaptation of CARS into the local context and acceptability of the proposed protocol prior to presenting the model to an expert panel. In the absence of national guidelines and frameworks regarding risk assessment and management for diabetes and CVD in the UAE, an expert panel forum was tasked to develop a consensus on the proposed screening programme. Prospective panellists were identified through extensive online search; evaluating experts' specialty, experience and research involvement. Shortlisted experts, including two cardiologists, two endocrinologists and two senior clinical pharmacists, were invited to participate in the forum. The Delphi technique was used to help arrive at a consensus on a specific question in one or more rounds-supportive documents were created to aid in voting and to calculate the level of agreement. ${ }^{25}$ The Delphi discussion focused on locally appropriate methods for absolute cardiovascular and diabetes risk assessment, including use of absolute CVD risk assessment and other multifactorial risk algorithm cut-offs; selection of screening tools; and risk factor thresholds for physician referrals. The following questions were discussed during the forum:

1. When should the participant's blood pressure (BP) measurement be taken? Moreover, what is the minimum time interval needed between taking the two BP readings? 
2. Which tool to use to calculate participants' absolute CVD risk?

3. Which method would be most suitable for calculating the participants' absolute CVD risk in the community pharmacy setting?

4. Which self-reported tool to use to determine the participants' risk of having T2DM? What absolute CVD risk threshold should be used when deciding to refer a participant to a physician?

5. At what glycated haemoglobin (HbA1c) level should a participant be referred to a physician?

6. Should at-risk participants who are referred to physicians for further testing be contacted to ask about any lifestyle modifications and outcomes of a visit to a physician? And should the physicians whom the referred participants visited be contacted?

The screening model planning involved the development of resources in supporting pharmacists-delivered screening including training manual, data collection tools and patient follow-up documents. These were developed through a process of co-production in consultation with the international co-researchers who had previous experience in pharmacist-delivered screening services. To ensure local context applicability, study materials were sent to three local community pharmacists for feedback and comments.

\section{Phase II: implementation phase}

Community pharmacists were trained through a faceto-face workshop that lasted for 3 hours on the study protocol, and on how to (1) approach potential participants, (2) use point-of-care testing devices, (3) handle refusals to participate, (4) collect data, (5) communicate risk assessment results to participants, (6) engage and refer at-risk individuals to physicians, (7) counsel participants on required lifestyle changes and (8) respond to participants' questions.

\section{Study setting and participants}

A purposive sample of 12 community pharmacies (with necessary infrastructure) in the three emirates of Dubai, Sharjah and Ajman in the UAE was selected. The recruited sites represented chain pharmacies. Study pharmacists were offered a small monetary incentive (AED 23 (equivalent to US\$6)) per screening in appreciation of their time and effort.

\section{Recruitment of participants}

Pharmacy-based advertising, including posters and flyers, were used to recruit participants. Individuals were mainly invited directly by the pharmacists to participate based on their judgement of the individual's age. Interested voluntary participants were prescreened by the pharmacists to determine their eligibility. Eligible participants were given written patient information sheet and they signed a consent form.

\section{Inclusion criteria}

- Arabic or English speaking.
- Aged between 40 and 74 years. There is no international consensus on the age range for diabetes screening; however, 40 years is recommended in several guidelines and was therefore considered appropriate.

\section{Exclusion criteria}

- Previous diagnosis of diabetes or CVD.

- Use of medications for treatment of diabetes, hypertension or any other CVD at the time of screening.

- Pregnancy.

- Terminal illness.

- Severe mental illness.

\section{Data collection and risk factor assessment}

To document the screening process, participating pharmacists completed brief paper-based records of each screening undertaken. This provided patient risk assessment data, documentation of patient counselling (eg, lifestyle factors assessed, targets specified and criteria for referral to a physician) and logistical information (eg, time taken to conduct screening and counselling, number of visits required, reasons for deviating from suggested screening schedule).

After checking eligibility and obtaining consent, trained pharmacists screened participants with the following measurements:

- Anthropometric measurements: weight, height and waist circumference were measured along with body mass index (BMI) calculations.

- Point-of-care testing: total cholesterol (TC), highdensity lipoprotein (HDL) cholesterol, low-density lipoprotein (LDL) plasma levels and glycated haemoglobin (HbAlc) level were measured using a fingerprick point-of-care testing device (Roche Cobas b 101 POC dual system). Systolic blood pressure (SBP) and diastolic blood pressure (DBP) were measured after participants rested for $5 \mathrm{~min}$ using the Omron 1A1B automated blood pressure (BP) monitor. Pharmacists advised participants to seek immediate medical attention if SBP was $\geq 180 \mathrm{~mm} \mathrm{Hg}$ or DBP $\geq 110 \mathrm{~mm} \mathrm{Hg}$. Pharmacists also reminded at-risk individuals that point-of-care tests may not have the same sensitivity and specificity as laboratory-based equipment, and hence, the need to refer to the medical practice for confirmation.

- CVD risk assessment: projected 10-year atherosclerotic CVD (ASCVD) risk was calculated for each participant.

- Diabetes risk assessment: in addition to HbAlc level, the American Diabetes Association (ADA) T2DM risk questionnaire was completed.

- Patient history: detailed sociodemographic information, brief medical history, family history of diabetes, smoking status, physical activity and dietary behaviours. Patients referral and follow-up: participants at high risk, defined as having any of the following: (1) 10-year ASCVD risk $\geq 7.5 \%$, (2) HbA1c level $\geq 5.7$, 
(3) ADA T2DM risk questionnaire $\geq 5$ points, were advised to visit their physician. All participants identified, by pharmacists, as at high risk for either CVD or diabetes were given a referral letter summarising pharmacy screening results to the physician for further testing. A rapid phone follow-up of all participants was conducted (within 2 weeks of screening) by a member of the research team to determine participants' satisfaction and experience with the pharmacy screening service. Participants were asked about perceived depth and clarity of pharmacist explanation of diabetes and CVD risk; their satisfaction with the risk assessment and the quality of testing and advice; instructions on the need for further evaluation by a physician; and the perceived length of the screening. They were also asked about their opinion on community pharmacies as a venue of the screening service, whether screening should be routinely provided by community pharmacists, and their willingness to pay for future pharmacistdelivered screening.

The follow-up also included questions about selfreported health status, frequency and pattern of physician visits in the past year. Participants were asked if they had undergone an assessment of lifestyle that affects diabetes and/or CVD risk by any healthcare professional in the past year or whether they were advised of the need to reduce their diabetes or CVD risk. The research team members identified themselves as such to the participants and informed them that their responses would not be communicated to the pharmacists who performed the screening.

\section{Outcomes}

1. Development of UAE pharmacy-based screening model.

A consensus statement from the expert panel detailing the screening processes, cut-off points/levels and referral mechanisms to physicians, all suited to the community pharmacy context in the UAE.

2. Feasibility assessment.

a. The proportion of screened participants identified as having high CVD risk (ASCVD 10-year risk defined as $\geq 7.5 \%$ as determined by the expert panel, see the Consensus statement on screening intervention section).

b. The proportion of participants identified as having elevated blood glucose (high Alc level $>6.5 \%$ (48mmol/ mol)) or high self-reported diabetes risk (T2DM risk questionnaire score $\geq 5$ points-as determined by the expert panel, see the Consensus statement on screening intervention section).

c. Participants' acceptability and satisfaction with the pharmacist-delivered screening.

\section{Patient and public involvement}

We did not involve patients or the public in our work.

\section{Data analysis}

The data were entered into Microsoft Access and 10\% of participant files were randomly selected for validation. Stata V.14 (StataCorp, College Station, Texas, USA) was used for data analysis. ${ }^{26}$ Normally distributed continuous variables were described using means and SD (such as participants' age, visits to physicians and nutritional habits). Categorical variables were described using counts and frequencies (such as demographic data, BMI (grouped) and medical history). The $\chi^{2}$ test was used to test differences in risk factors by age and gender. A $p$ value of $<0.05$ was considered statistically significant.

\section{RESULTS \\ Consensus statement on screening intervention}

The expert panel reached a consensus on the use of absolute risk assessment and other multifactorial risk algorithm cut-offs, screening tools and risk factor thresholds. Panel members unanimously agreed on taking two seated measurements of $\mathrm{BP}$ after a $5 \mathrm{~min}$ rest and separated by $2 \mathrm{~min}$. If the two SBP and DBP readings differed by $\geq 10 \mathrm{~mm} \mathrm{Hg}$ or $\geq 6 \mathrm{~mm} \mathrm{Hg}$, respectively, a third measurement would be needed, and the two closest readings would be used to calculate mean BP. Regarding the calculation of 10-year ASCVD risk score, the American College of Cardiology/American Heart Association (ACC/AHA) pooled cohort equations CVD risk calculator should be used. Participants having a 10-year risk $\geq 7.5 \%$ were classified as high risk and had to be referred to a physician for further testing. The official ASCVD Risk Estimator Plus smartphone application with off-line feature was deemed most feasible to perform the calculation. Other criteria that independently necessitated referral to a physician were an HbA1c level exceeding 5.7\% (pre-diabetes) or a score above five points on the ADA questionnaire to measure the risk of T2DM.

Regarding the determination of uptake of referral and physician action on the results of the screening, the panellists identified the impracticality of contacting physician's offices; instead, it was agreed that uptake of referral and physician action would be best reported by participants themselves during follow-up calls. Clinical training manual and implementation resources were developed to ensure systematic approaches for the execution of pharmacist-delivered screening and to minimise variability among participating pharmacists. Data collection tools and consent forms were adapted from the CARS project. Figure 1 illustrates the final screening model.

\section{Sociodemographic and health characteristics}

From 15 December 2017 to 8 May 2018, 120 consenting participants were screened for CVD and T2DM from the population visiting the 12 participating community pharmacies (which had sufficient/appropriate space to accommodate the screening service, and had high volume and variability in clientele). Five participants were excluded for not meeting the study criteria. Sociodemographic and 


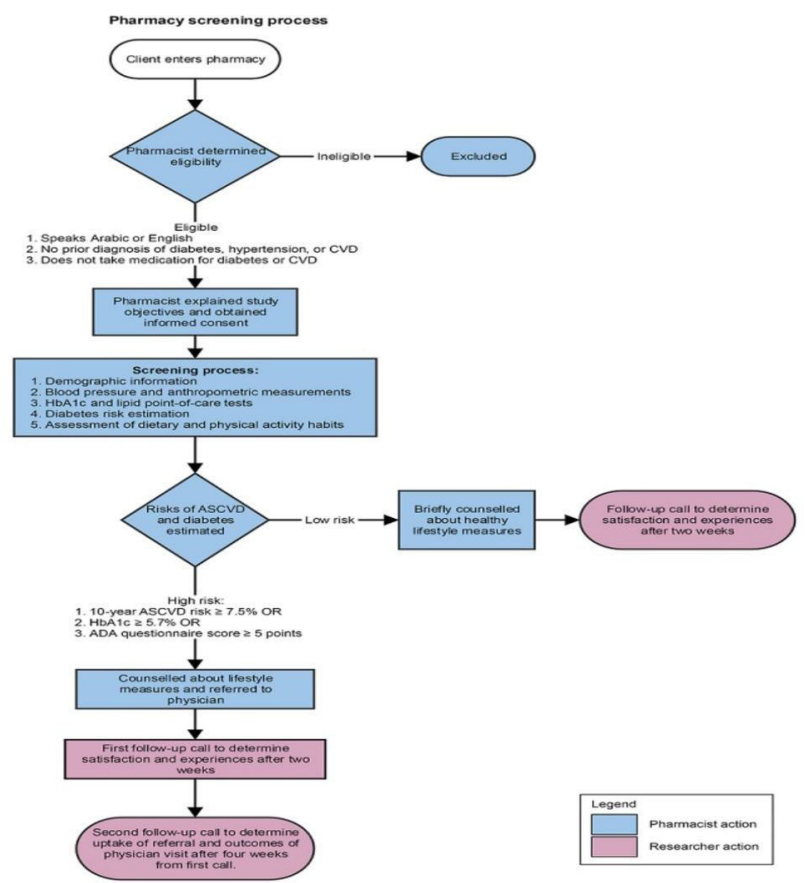

Figure 1 Pharmacy screening model in the United Arab Emirates (UAE). ADA, American Diabetes Association; ASCVD, atherosclerotic cardiovascular disease; CVD, cardiovascular disease; HbA1c, glycated haemoglobin.

health characteristics of the 115 screened participants are summarised in table 1 . Gender representation was almost equal, with most participants having been born in Syria and Egypt. When participants were asked about their present state of health, 32\% reported being 'excellent'. On average, participants visited a physician three times a year. Twenty-four per cent of participants reported having regular physicians, while $18.6 \%$ had regular clinic but visited different physicians, and $38.6 \%$ visited different clinics. In the past 12 months, only $6.4 \%$ reported undertaking a detailed examination of lifestyle factors by a health professional.

\section{Implementation fidelity}

Of the screened participants, $57.4 \%$ were identified as high risk for diabetes and/or CVD. After each screening encounter, pharmacists completed a checklist that documented the screening process (table 2). Most participants $(91.7 \%)$ were screened immediately following their recruitment and the signing of informed consent, and the remainder were given appointments for a later time. In the majority of cases $(92.3 \%)$, the entire screening process was completed during a single visit to the pharmacy.

A total of 12 participants did not undergo a complete assessment as per the screening protocol. A full lipid profile was not obtained in four cases, and four other participants did not obtain an HbAlc measurement. Furthermore, pharmacists did not perform a waist circumference measurement for three participants and BP measurement for one participant. Pharmacists documented the reasons for incomplete assessments for these 10 participants: a technical error in the POC device
Table 1 Demographic and health characteristics $(n=115)$

\begin{tabular}{lll} 
Characteristic & N & (\%) \\
\hline Gender & & \\
Female & 60 & $(52.1)$ \\
Age (years) & & \\
Mean \pm SD & 47.23 & \pm 7.3 \\
Nationality & & \\
Syria & 32 & $(27.8)$ \\
Egypt & 23 & $(20.0)$ \\
India & 11 & $(9.5)$ \\
Jordan & 7 & $(6.0)$ \\
Pakistan & 7 & $(6.0)$ \\
Other & 35 & $(30.4)$
\end{tabular}

\section{Education}

$\begin{array}{lll}\text { Not educated } & 2 & (1.7) \\ \text { Primary/middle school } & 15 & (13.0) \\ \text { High school } & 37 & (36.2) \\ \text { University } & 50 & (43.4) \\ \text { Marital status } & & \\ \text { Married } & 103 & (89.5) \\ \text { Single } & 8 & (6.9) \\ \text { Divorced } & 3 & (2.6) \\ \text { Widowed } & 1 & (0.8)\end{array}$

Employment

$\begin{array}{lll}\text { Full-time } & 67 & (63.2) \\ \text { Part-time } & 6 & (5.6) \\ \text { Home duties } & 25 & (23.5) \\ \text { Other } & 17 & (14.7)\end{array}$

Self-reported health status*

$\begin{array}{lll}\text { Excellent } & 24 & (32.0) \\ \text { Good } & 41 & (54.6) \\ \text { Average } & 10 & \text { (13.3) }\end{array}$

$\begin{aligned} & \text { No. of visits to a physician in the } \\ & \text { past year* } \\ & \text { Mean } \pm \text { SD }\end{aligned} \quad 3.05 \quad \pm 4.1$

$\begin{array}{lll}\text { Patterns of physician use } & & \\ \text { Have a regular physician } & 18 & (24.0) \\ \begin{array}{l}\text { Have a regular clinic but often see } \\ \text { different physicians }\end{array} & 14 \\ \begin{array}{l}\text { Visit different physician clinics } \\ \text { Rarely or never visit a physician }\end{array} & 29\end{array}$

\section{Source of advice to reduce risk of} diabetes and CVD risk in the past 12 months (apart from pharmacy screening visit)*

\begin{tabular}{lll} 
A physician & 13 & $(17.5)$ \\
A dietitian & 1 & $(1.3)$ \\
A specialist physician & 5 & $(6.7)$ \\
\hline
\end{tabular}




\begin{tabular}{lll}
\hline Table 1 Continued & N & (\%) \\
\hline Characteristic & 2 & $(2.7)$ \\
\hline A pharmacist & 9 & $(12.1)$ \\
$\begin{array}{l}\text { Others practitioners } \\
\text { A family member }\end{array}$ & 7 & $(9.4)$ \\
$\begin{array}{l}\text { Examination of lifestyle factors } \\
\text { that affect diabetes and CVD risk } \\
\text { by a health professional during } \\
\text { the past } 12 \text { months* }\end{array}$ & 7 & $(6.4)$ \\
\hline
\end{tabular}

*Number of participants is 75 (first follow-up phone call). CVD, cardiovascular disease.

prevented the measurement in nine cases, and the participant objected to the measurement in one case. Assessments of diabetes risk as per the ADA questionnaire, dietary habits and physical activity habits were completed for all participants. On average, assessment and testing took $27 \pm 9.4 \mathrm{~min}$.

In all cases where pharmacists documented postassessment counselling, pharmacists explained the meaning of participants' ASCVD and ADA questionnaire risk scores and the targets for suboptimal blood test results. HbA1c test results were explained to $96.3 \%$ of participants. Regarding lifestyle behaviours, the pharmacists documented counselling $85.8 \%$ and $81.1 \%$ of participants about healthy diet and physical activity, respectively. Finally, pharmacists reported informing $87.9 \%$ of participants of the need for confirmatory testing at the physician's office. Pharmacists reported that post-assessment counselling lasted $11.6 \pm 6.5 \mathrm{~min}$ on average.

\section{Uptake of referral}

A total of $71(61.7 \%)$ at-risk individuals were referred to their physicians for further testing; 37 participants $(52.1 \%)$ completed the second follow-up survey to determine uptake of referral (table 3). Only nine of these participants $(24.3 \%)$ had visited their physician following the screening, $29.7 \%$ had not visited their physician yet but intended to do so. Conversely, $43.2 \%$ did not visit their physician and made no such plans (table 3 ).

Five participants told their physicians about the pharmacy screening results; four of the five cases reported that physicians took the results seriously. Physicians ordered follow-up tests for $77.7 \%$ of the participants, including TC and blood sugar levels (57.1\% each), HDL levels and BP (42.8\% each).

When asked about lifestyle changes that participants adopted following the screening, $63.1 \%$ reported improved diet, $57.8 \%$ attempted to lose weight and $40 \%$ started new medications since the screening (table 3).

Participants' experiences, feedback and satisfaction with the screening service

All participants were contacted by telephone to determine their experiences and satisfaction with the pharmacy screening service (table 4 ). A total of 75 participants
Table 2 Pharmacist-documented components of screening model completed $(n=112)$

\begin{tabular}{lll}
\hline Component of screening model & $\mathbf{N}$ & (\%) \\
\hline Timing of screening & & \\
\hline Immediately following recruitment & 100 & $(91.7)$ \\
\hline $\begin{array}{l}\text { By appointment on same day } \\
\text { By appointment on another day }\end{array}$ & 3 & $(2.8)$ \\
$\begin{array}{l}\text { No. of visits needed to complete } \\
\text { screening }\end{array}$ & & $(5.5)$ \\
\hline $\begin{array}{l}\text { One visit } \\
\text { Two visits }\end{array}$ & 103 & $(92.3)$ \\
\hline
\end{tabular}

Assessments and measurements completed

$\begin{array}{lll}\text { Anthropometric measurements } & 110 & (100.0) \\ \text { Diabetes risk assessment } & 111 & (100.0) \\ \text { ASCVD risk score calculation } & 110 & (100.0) \\ \text { Dietary habits assessment } & 111 & (100.0) \\ \text { Physical activity habits assessment } & 111 & (100.0)\end{array}$

Tests and measurements not completed

\begin{tabular}{lll} 
Lipid profile & 4 & $(33.3)$ \\
\hline HbA1c & 4 & $(33.3)$ \\
Waist circumference & 3 & $(25.0)$ \\
\hline $\begin{array}{l}\text { Blood pressure } \\
\text { Reason for not completing test/ } \\
\text { measurement }\end{array}$ & 1 & $(8.33)$ \\
\hline $\begin{array}{l}\text { Technical error in device } \\
\text { Participant objection* }\end{array}$ & 9 & \\
\hline
\end{tabular}

\section{Assessment, testing and} measurement duration

$\begin{array}{lll}\text { Mean duration } \pm S D(\min ) & 27.0 \pm 9.4 \\ 10-20 & 34 & (30.9) \\ 21-30 & 53 & (48.2) \\ 31-40 & 19 & (17.3) \\ \text { Over } 40 & 4 & (3.6)\end{array}$

Post-assessment counselling

$\begin{array}{lll}\text { ASCVD risk score interpretation } & 110 & (100.0) \\ \text { ADA questionnaire score } & 107 & (100.0)\end{array}$

interpretation

$\begin{array}{lll}\text { HbA1c result interpretation } † & 79 & \text { (96.3) } \\ \text { Guideline targets for suboptimal blood } 107\end{array}$

test results

\section{Lifestyle behaviours (top two covered aspects)}

$\begin{array}{lll}\text { Dietary behaviours } & 91 & (85.8) \\ \text { Physical activity } & 86 & (81.1) \\ \begin{array}{l}\text { Need for further/confirmatory testing } \\ \text { at physician's office }\end{array} & 87 & (87.9)\end{array}$

Post-assessment counselling duration

Continued 
Table 2 Continued

\begin{tabular}{lll}
\hline Component of screening model & $\mathbf{N}$ & $\mathbf{( \% )}$ \\
\hline Mean duration $\pm \mathrm{SD}(\mathrm{min})$ & $11.6 \pm 6.5$ & \\
$1-10$ & 39 & $(33.9)$ \\
$11-20$ & 36 & $(31.3)$ \\
$21-30$ & 3 & $(2.6)$ \\
Not reported & 37 & $(32.2)$ \\
\hline
\end{tabular}

*One participant objected to waist circumference measurement. †Documentation was missing for 30 participants.

ADA, American Diabetes Association; ASCVD, atherosclerotic cardiovascular disease; $\mathrm{HbA} 1 \mathrm{c}$, glycated haemoglobin.

completed the follow-up survey $(65.2 \%)$. In $68 \%$ of the cases, the pharmacist-initiated the conversation about the screening service. Other participants reported learning about the service from personal acquaintances (17.3\%) and social media $(10.7 \%)$.

Almost all participants reported that the pharmacists' explanation of their risk of developing diabetes or CVD were either 'very clear' or 'clear enough' and that pharmacists explained the various lifestyle causes of increased CVD or diabetes risk 'very comprehensively' or 'discussed several issues'.

At the conclusion of the screening, $94.5 \%$ of participants reported that pharmacists made sure participants understood all key points, and $89.3 \%$ indicated that pharmacists provided participants with a written screening report.

Most participants $(94.5 \%)$ reported either being 'satisfied' or 'very satisfied' with the risk assessment undertaken by the pharmacists and the quality of the pharmacists' advice.

Eighty-six per cent of participants thought pharmacies are good venues for conducting screening tests, and $86.6 \%$ thought pharmacists should routinely provide CVD and diabetes risk screening. Most participants $(82.7 \%)$ indicated they would be willing to pay for pharmacistdelivered screening services should it be provided in the future (table 3).

\section{DISCUSSION}

This study is the first in an Arabic-speaking country (UAE) to assess the feasibility and performance of an evidencebased pharmacist-delivered screening programme for T2DM and CVD. The screening model, adapted from the CARS model with the advice of local experts, was successfully implemented in community pharmacies and resulted in the identification and referral of at-risk individuals. ${ }^{24}$

The proportion of screened participants identified with high diabetes or CVD risk in this study was higher compared with reported rates in the international pharmacy screening literature. This could be partially explained by the higher prevalence of diabetes and CVD in the UAE. ${ }^{20} 27$ The high referral rate $(61.7 \%)$ in this
Table 3 Outcomes of at-risk participants' referral $(n=37)$

\begin{tabular}{|c|c|c|}
\hline & $\mathbf{N}$ & $(\%)$ \\
\hline $\begin{array}{l}\text { Participants completed uptake of referral } \\
\text { follow-up }\end{array}$ & 37 & $(52.1)$ \\
\hline $\begin{array}{l}\text { Participants visited a doctor to discuss } \\
\text { pharmacist-delivered screening results }\end{array}$ & 9 & $(24.3)$ \\
\hline Visited doctor straight away & 6 & $(16.2)$ \\
\hline Made some changes and went to doctor later & 1 & $(2.7)$ \\
\hline Discussed results at routine visit & 2 & $(5.4)$ \\
\hline Participants who did not visit a doctor & 28 & $(75.6)$ \\
\hline Have not visited doctor yet but intend to & 11 & $(29.7)$ \\
\hline Did not think it was necessary & 1 & $(2.7)$ \\
\hline $\begin{array}{l}\text { Have not visited doctor yet and made no } \\
\text { plans }\end{array}$ & 16 & $(43.2)$ \\
\hline Physician knew about pharmacy screening & 5 & $(55.5)$ \\
\hline Referral letter given to the doctor & 2 & $(40.0)$ \\
\hline Told doctor about pharmacy screening & 3 & $(60.0)$ \\
\hline $\begin{array}{l}\text { Doctor treated the results of pharmacy } \\
\text { screening seriously }\end{array}$ & 4 & $(80.0)$ \\
\hline $\begin{array}{l}\text { Follow-up tests were undertaken by the } \\
\text { physician }\end{array}$ & 7 & $(77.7)$ \\
\hline Blood pressure & 3 & $(42.8)$ \\
\hline Total cholesterol & 4 & $(57.1)$ \\
\hline HDL cholesterol & 3 & $(42.8)$ \\
\hline Blood sugar level & 4 & $(57.1)$ \\
\hline Waist & 1 & $(14.2)$ \\
\hline Weight & 2 & (28.5) \\
\hline Other & 4 & $(44.4)$ \\
\hline \multicolumn{3}{|l|}{ Lifestyle changes since screening } \\
\hline Increased regular exercise & 7 & (36.8) \\
\hline Attempted to lose weight & 11 & $(57.8)$ \\
\hline Improved diet & 12 & $(63.1)$ \\
\hline Started new medications & 4 & $(40.0)$ \\
\hline
\end{tabular}

HDL, high-density lipoprotein.

study is consistent with the recent trend towards higher rates of referral. ${ }^{17}$ Without systematic diabetes and CVD screening programme in the primary care setting in the UAE, lack of universal healthcare coverage, all in tandem with poor health-seeking behaviour and the delay in access to medical services these conditions are likely to continue to be undiagnosed. The potential, therefore, exists for community pharmacists who have regular contact with the population to improve access to health screening services and promote public health awareness.

Several pharmacy and pharmacist-level factors at selected pharmacies contributed to the success of implementing pharmacist-delivered screening, these include (1) the necessary infrastructure (such as sufficient/appropriate space) to accommodate the screening service, (2) motivation of the pharmacist to learn about and perform 
Table 4 Participants' experiences, feedback and satisfaction with screening $(n=75)$

\section{N (\%)}

Experience and feedback on pharmacist-

delivered screening

\begin{tabular}{|c|c|c|c|}
\hline \multirow{5}{*}{$\begin{array}{l}\text { Person who initiated the conversation about } \\
\text { screening between participant and pharmacist }\end{array}$} & Another participant in the project & 1 & $(1.3)$ \\
\hline & Pharmacist & 51 & $(68.0)$ \\
\hline & Pharmacy staff & 2 & $(2.7)$ \\
\hline & Acquaintance & 13 & (17.3) \\
\hline & Social media & 8 & $(10.7)$ \\
\hline \multirow{4}{*}{$\begin{array}{l}\text { Clarity of pharmacist's explanation of risk of } \\
\text { developing diabetes and CVD }\end{array}$} & Very clear & 59 & $(78.7)$ \\
\hline & Clear enough & 14 & $(18.7)$ \\
\hline & Some parts clear & 1 & (1.3) \\
\hline & Generally unclear & 1 & $(1.3)$ \\
\hline \multirow{3}{*}{$\begin{array}{l}\text { Depth of pharmacist's exploration of possible } \\
\text { lifestyle causes of increased diabetes and } \\
\text { CVD risks }\end{array}$} & Very comprehensive & 57 & $(76.0)$ \\
\hline & Discussed several issues & 13 & (17.3) \\
\hline & Discussed only one issue & 7 & $(9.3)$ \\
\hline \multirow[t]{3}{*}{ Steps undertaken following screening } & $\begin{array}{l}\text { The pharmacist provided you with a written report of your } \\
\text { results }\end{array}$ & 67 & (89.3) \\
\hline & The pharmacist made sure that you understood everything & 69 & $(94.5)$ \\
\hline & $\begin{array}{l}\text { The pharmacist clearly stated when the physician follow-up } \\
\text { was required }\end{array}$ & 24 & $(33.8)$ \\
\hline \multirow[t]{4}{*}{ Quality of the testing carried out in pharmacy } & Excellent & 53 & $(70.7)$ \\
\hline & Above average & 12 & $(16.0)$ \\
\hline & Average & 6 & $(8.0)$ \\
\hline & Slightly below average & 4 & $(5.3)$ \\
\hline \multirow{4}{*}{$\begin{array}{l}\text { Perceived length of the diabetes and CVD risk } \\
\text { screening process }\end{array}$} & Much too long & 2 & $(2.7)$ \\
\hline & A little long & 12 & $(16.0)$ \\
\hline & About right & 58 & $(77.3)$ \\
\hline & A little short & 3 & $(4.0)$ \\
\hline
\end{tabular}

Satisfaction with the pharmacist-delivered screening

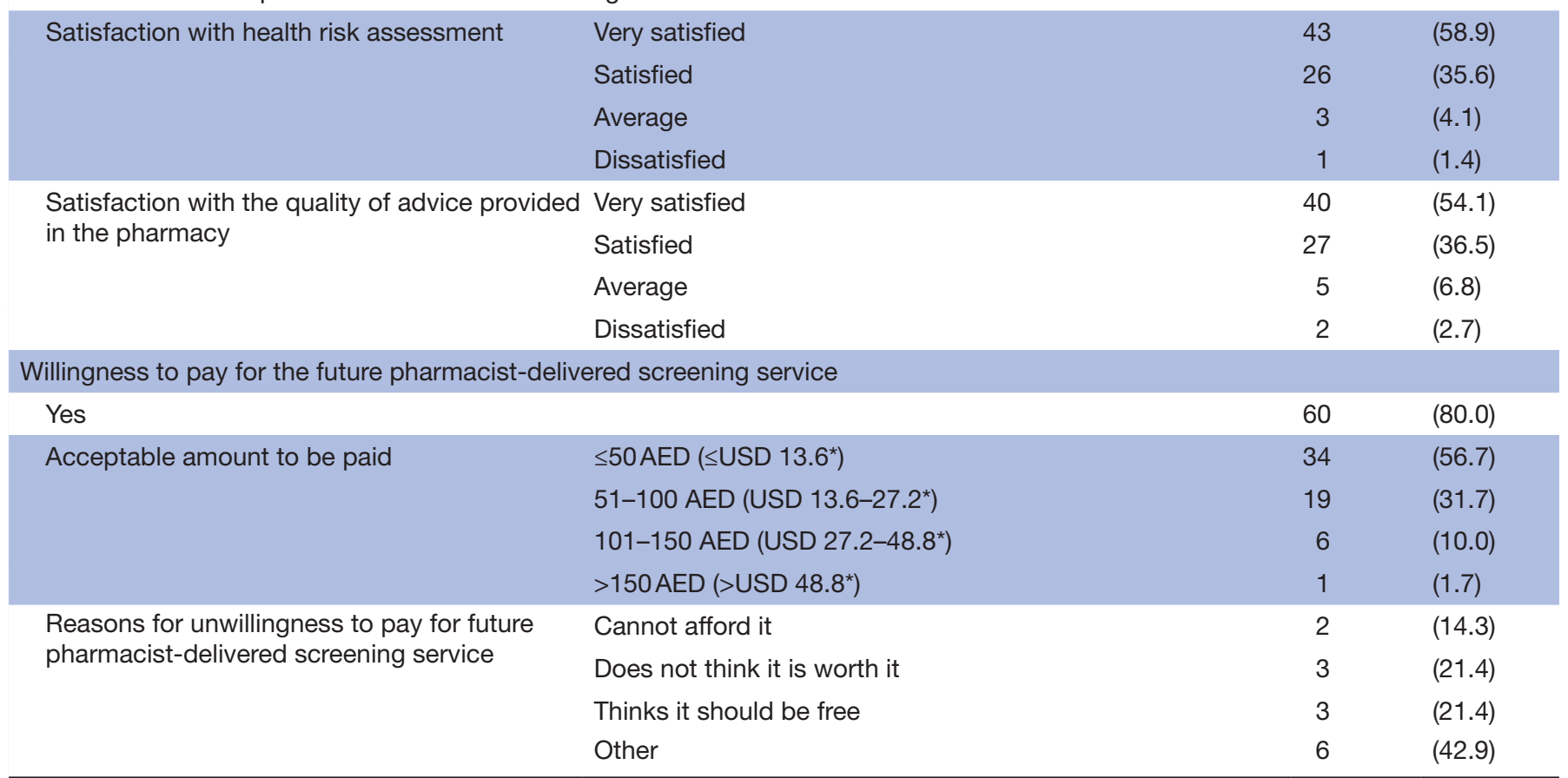

CVD, cardiovascular disease. 
the screening and (3) the high volume and variability in clientele.

The purposive sampling of community pharmacies and the exploratory study design might have limited the generalisability of study results. However, equally, it could be argued that the somewhat driven community pharmacists in this study would have been representative of the expected pharmacists in future programme roll-out. The study was designed to demonstrate the feasibility of pharmacist-delivered screening and to understand how implementation support and processes might have been optimised to enable such a health service. Follow-up with physicians on pharmacist-delivered screening was not carried out as per the expert panel advice due to the complexity of access to physician services and different health coverage/schemes, lack of integration and communication between services provided at the government and private institutions, the current lack of integration of pharmacy services with other healthcare services and the scattered primary care structure in the country. Such lack of follow-up with physicians is not uncommon in studies exploring early stages of pharmacy-based screening given the complexity of the primary care setting. To optimise the health impacts of a screening service, a more effective referral pathway will need to be established in further discussions between pharmacists and physicians. Better uptake of screening may have been achieved with training of other staff in the pharmacy to aid in recruitment. A focused advertising campaign, including advertorials in local media, may also have boosted uptake. A better follow-up rate may have been achieved if the pharmacist him/herself followed up screened participants several weeks after the referral was advised. In this follow-up, the pharmacist could check if at-risk screened individuals had taken up the referral or prompt them to act on it if had they not done so. It may also have been helpful to send a copy of the referral directly to the referred individual's nominated physician. It could also have been that participants still questioned the validity of the risk screening process carried out in community pharmacies, and that they could have taken its results more seriously had it been carried out in a clinic or a more traditional care setting. Patient and physician reservations about services being provided in community pharmacies have been reported in the literature. In the UAE, reasons cited for this included doubt about pharmacist competence to provide the services, a business image rather than a healthcare image of community pharmacy that prevails in the country, little privacy in the pharmacy setting and lack of effective collaboration between pharmacists and physicians. ${ }^{28-30}$ For community pharmacies to be an acceptable setting for providing screening services in the UAE, the service model in the pharmacy will need to assure minimum expectations of patients including patient privacy and properly trained pharmacists. We acknowledge that the focus of this trial was on determining feasibility from a health service perspective. However, it seems relevant to point out that the original CARS model, which we adapted, did engage with a diverse range of Australian consumers $(n=46)$ before design completion to support model acceptability and patient engagement. This included 20 Arabic-speaking migrants, 10 male and 10 female in separate focus groups facilitated by the lead investigator HA, to explore various aspects of a pharmacy screening service from a culturally and linguistically diverse consumer perspective. This process established the generally acceptable parameters for a pharmacist-delivered service from the perspective of Middle Eastern adults, arguably validated by the strong satisfaction with the intervention reported in patient surveys. In these focus groups, there were a number of comments suggesting greater confidence and trust in Arabic pharmacists and pharmacy systems than their Australian counterparts. What this process missed was consumer guidance regarding their specific support needs in the context of this model being operated in within the UAE health system. We have relied on health professionals and experts for guidance on this because of the complexity of the health system, absence of primary care and the novelty of the intervention, which required a significant level of insight and extensive engagement to determine a model that might work. We fully acknowledge that we need to engage UAE consumers further before scaling up this intervention.

Participant selection was heavily based on pharmacist perception of their age. Until screening becomes known and accepted as a community pharmacy service in UAE, the most likely pathway to uptake of screening in community pharmacy in the UAE is by direct invitation from a pharmacist. It is also likely to yield more individuals at high risk and in need of further testing and diagnosis. This has also been the case in other screening trials (Krass et $a l^{31}$ CARS trial). Once such service becomes established, it is likely that consumers may request it themselves in response to advertising, posters in the pharmacy and so on. The six-dollar per participant was an incentive for the pharmacists to engage in the study, and it was not based on a calculation of what an actual service would cost. Future studies should aim to establish effectiveness of the pharmacist-delivered screening model for diabetes and CVD in the UAE, and generate evidence of its costeffectiness. Then pharmacists' remuneration would eventually need to be negotiated with government and private insurance. At this point, this was not within the scope of this study.

The research team, at the planning phase, aimed to document the proportion of patients approached, the proportion of those who consented to be screened and the reason(s) for individual refusal to be screened. However, pharmacists reported that this would be an added work and preferred not to collect such data. The short follow-up period with patients was perhaps inadequate to capture all further diagnostic and management activities as a result of pharmacist-delivered screening. This feasibility study was continued on a larger scale to evaluate the efficacy of pharmacist-delivered screening in 
identifying participants with high diabetes and/or CVD risk in the UAE. Additional future studies should evaluate strategies to establish closer links between community pharmacy and physicians in primary care, creating structured referral pathways and emphasis on interprofessional coordination between pharmacists and physicians.

\section{CONCLUSIONS}

It is feasible for community pharmacists to screen and refer individuals for diabetes and CVD risks in the UAE. The successful implementation of the screening model in community pharmacy, in terms of identifying at-risk individuals and advising them to visit their physicians for further evaluation, offers a new platform to increase screening capacity within the primary care setting, and represents a key opportunity for the early detection and intervention to tackle the increasing burden of both diseases. However, pathways for the integration of the pharmacist-delivered screening service with physicians in primary care are yet to be explored.

\section{Author affiliations}

${ }^{1}$ Pharmacy Practice \& Pharmacotherapy, University of Sharjah, College of Pharmacy, Sharjah, United Arab Emirates

${ }^{2}$ Center for Global Health Delivery-Dubai, Harvard Medical School, Dubai, United Arab Emirates

${ }^{3}$ Ajman University of Science and Technology College of Pharmacy and Health Science, Ajman, United Arab Emirates

${ }^{4}$ Deakin Rural Health, School of Medicine, Deakin University, Geelong, Victoria, Australia

${ }^{5}$ Institute for Healthcare Transformation, Deakin University, Geelong, Victoria, Australia

${ }^{6}$ Faculty of Pharmacy, University of Sydney, Sydney, New South Wales, Australia

Acknowledgements The authors sincerely thank study participants for their time, and participating pharmacists and pharmacies including Bin Sina Group, Makkah Group and Al Seha Wal Jamal Group. Special thanks for the field team of brilliant pharmacists: Mr Ward Saidawi, Ms Safa Al Awad, Ms Amna Othman and Ms Lujain Aloum for their exceptional efforts in data collection/management and postimplementation support. The authors are grateful for valuable input from Professor Rifat Atun, School of Public Health, Harvard University.

Contributors HTA designed the study, supervised data collection process, assisted with data analysis, wrote, reviewed and edited the entire manuscript. SC and RC analysed data, reviewed and edited manuscript. SH wrote parts of manuscript. $\mathrm{KM}$ and IK assisted with designing of the study, reviewed the methods and data analysis contributed to the discussion, and reviewed all drafts.

Funding This research was supported by two research grants: (1) the research cooperative grant from Center for Global Health Delivery-Dubai, Harvard Medical School, Harvard University (agreement No. 027562-746845-0302), (2) operational grant from the University of Sharjah.

Competing interests None declared.

\section{Patient consent for publication Obtained.}

Ethics approval This study was approved by the Research Ethics Committee of the University of Sharjah, the Ministry of Health and Prevention in the United Arab Emirates, and deemed Exempt by the Harvard T.H. Chan School of Public Health Institutional Review Board.

Provenance and peer review Not commissioned; externally peer reviewed. Data availability statement Data are available on reasonable request.

Open access This is an open access article distributed in accordance with the Creative Commons Attribution Non Commercial (CC BY-NC 4.0) license, which permits others to distribute, remix, adapt, build upon this work non-commercially, and license their derivative works on different terms, provided the original work is properly cited, appropriate credit is given, any changes made indicated, and the use is non-commercial. See: http://creativecommons.org/licenses/by-nc/4.0/.

\section{ORCID iD}

Hamzah Tareq Alzubaidi http://orcid.org/0000-0001-5122-271X

\section{REFERENCES}

1 Forouzanfar MH, Afshin A, Alexander LT, et al. Global, regional, and national comparative risk assessment of 79 behavioural, environmental and occupational, and metabolic risks or clusters of risks, 1990-2015: a systematic analysis for the global burden of disease study 2015. Lancet 2016;388:1659-724.

2 Unnikrishnan R, Pradeepa R, Joshi SR, et al. Type 2 diabetes: Demystifying the global epidemic. Diabetes 2017;66:1432-42.10.2337/db16-0766

3 Guariguata L, Whiting DR, Hambleton I, et al. Global estimates of diabetes prevalence for 2013 and projections for 2035. Diabetes Res Clin Pract 2014;103:137-49.

4 Ogurtsova K, da Rocha Fernandes JD, Huang Y, et al. IDF diabetes atlas: global estimates for the prevalence of diabetes for 2015 and 2040. Diabetes Res Clin Pract 2017;128:40-50.

5 Roth GA, Johnson C, Abajobir A, et al. Global, regional, and national burden of cardiovascular diseases for 10 causes, 1990 to 2015. J Am Coll Cardiol 2017;70:1-25.

6 Einarson TR, Acs A, Ludwig C, et al. Prevalence of cardiovascular disease in type 2 diabetes: a systematic literature review of scientific evidence from across the world in 2007-2017. Cardiovasc Diabetol 2018;17:83.

7 Beagley J, Guariguata L, Weil C, et al. Global estimates of undiagnosed diabetes in adults. Diabetes Res Clin Pract 2014;103:150-60.

8 The 10-year cost-effectiveness of lifestyle intervention or metformin for diabetes prevention. An intent-to-treat analysis of the DPP/ DPPOS. 2012;35:723-30.

9 Lindström J, llanne-Parikka P, Peltonen $\mathrm{M}$, et al. Sustained reduction in the incidence of type 2 diabetes by lifestyle intervention: follow-up of the Finnish diabetes prevention study. Lancet 2006;368:1673-9.

10 Siu AL. Screening for abnormal blood glucose and type 2 diabetes mellitus: U.S. preventive services Task force recommendation StatementScreening for abnormal blood glucose and type 2 diabetes mellitus. Ann Intern Med 2015;163:861-8.

11 Abuyassin B, Laher I. Diabetes epidemic sweeping the Arab world. World J Diabetes 2016;7:165-74.

12 Badran M, Laher I. Type II diabetes mellitus in Arabic-speaking countries. Int J Endocrinol 2012;2012:902873.

13 Alzubaidi H, Mc Narmara K, Kilmartin GM, et al. The relationships between illness and treatment perceptions with adherence to diabetes self-care: a comparison between Arabic-speaking migrants and Caucasian English-speaking patients. Diabetes Res Clin Pract 2015;110:208-17.

14 Alzubaidi H, Mc Namara K, Browning C, et al. Barriers and enablers to healthcare access and use among Arabic-speaking and Caucasian English-speaking patients with type 2 diabetes mellitus: a qualitative comparative study. BMJ Open 2015;5:e008687.

15 Alzubaidi H, Mc Mamara K, Chapman C, et al. Medicine-taking experiences and associated factors: comparison between Arabicspeaking and Caucasian English-speaking patients with Type 2 diabetes. Diabet. Med. 2015;32:1625-33.

16 Ayorinde AA, Porteous T, Sharma P. Screening for major diseases in community pharmacies: a systematic review. Int J Pharm Pract 2013;21:349-61.

17 Willis A, Rivers P, Gray LJ, et al. The effectiveness of screening for diabetes and cardiovascular disease risk factors in a community pharmacy setting. PLoS One 2014;9:e91157.

18 San-Juan-Rodriguez A, Newman TV, Hernandez I, et al. Impact of community pharmacist-provided preventive services on clinical, utilization, and economic outcomes: an umbrella review. Prev Med 2018;115:145-55.

19 Mc Namara KP, Dunbar JA, Philpot B, et al. Potential of pharmacists to help reduce the burden of poorly managed cardiovascular risk. Aust J Rural Health 2012;20:67-73.

20 Sulaiman N, Elbadawi S, Hussein A, et al. Prevalence of overweight and obesity in United Arab Emirates Expatriates: the UAE national diabetes and lifestyle study. Diabetol Metab Syndr 2017;9.

21 Alzubaidi H, Saidawi W, Mc Namara K. Pharmacist views and pharmacy capacity to deliver professional services in the United Arab Emirates. Int J Clin Pharm 2018;40:1106-15. 
22 Hasan S, Sulieman H, Chapman C, et al. Community pharmacy in the United Arab Emirates: characteristics and workforce issues. Int $J$ Pharm Pract 2011;19:392-9.

23 Green LW. Toward cost-benefit evaluations of health education: some concepts, methods, and examples. Health Educ Monogr 1974;2:34-64.

24 Mc Namara KP, Krass I, Peterson GM, et al. Implementing screening interventions in community pharmacy to promote interprofessional coordination of primary care - a mixed methods evaluation. Res Social Adm Pharm. In Press 2019.

25 McMillan SS, King M, Tully MP. How to use the nominal group and Delphi techniques. Int J Clin Pharm 2016;311:655-62.

26 StataCorp. Stata statistical software: release 14. College Station TSL, 2015.

27 Al Busaidi N, Shanmugam P, Manoharan D. Diabetes in the middle East: government health care policies and strategies that address the growing diabetes prevalence in the middle East. Curr Diab Rep 2019;19.

28 Hasan S, Stewart K, Chapman CB, et al. Physicians' perspectives of pharmacist-physician collaboration in the United Arab Emirates: Findings from an exploratory study. $J$ Interprof Care 2018;32:566-74.

29 Hasan S, Sulieman H, Stewart K, et al. Patient expectations and willingness to use primary care pharmacy services in the United Arab Emirates. Int J Pharm Pract 2015;23:340-8.

30 Hasan S, Stewart K, Chapman CB, et al. Physicians' attitudes towards provision of primary care services in community pharmacy in the United Arab Emirates. Int J Pharm Pract 2015;23:274-82.

31 Krass I, Mitchell B, Clarke P, et al. Pharmacy diabetes care program: analysis of two screening methods for undiagnosed type 2 diabetes in Australian community pharmacy. Diabetes Res Clin Pract 2007;75:339-47. 